\title{
ARTIGOS
}

\section{O VINHO DO PORTO: AUTENTICIDADE DE MARCA COMO PROMOTORA DO BRAND EQUITY}

\section{RESUMO}

A presente investigação teve como objectivo aprofundar o estudo do conceito de autenticidade de marca, aplicado a um dos mais importantes produtos da economia portuguesa: o vinho do Porto. Essa investigação adotou a técnica de observação direta extensiva. Foram inquiridos 261 indivíduos, por meio da aplicação de um questionário estruturado em suporte on-line. Estudou-se o relacionamento da dimensão de Autenticidade de Marca com os Elementos do Marketing Mix e as dimensões do Brand Equity, segundo o modelo de Yoo, Donthu e Lee (2000). Procurou-se perceber em que medida ter o reconhecimento do atributo de autenticidade, bem como sua interação com as estratégias percebidas de marketing pelos consumidores, pode ajudar a promover o capital de marca. Os principais resultados indicam claramente que a percepção do consumidor relativamente à autenticidade de marca é um determinante chave das Dimensões do Brand Equity, e o Brand Equity tem um impacto relevante no Passa-palavra Positivo. Os resultados desse estudo proporcionam aos gestores de marca uma melhor compreensão da importância que a autenticidade de marca desempenha na criação do Brand Equity. As contribuições práticas para

Ricardo Valins valins@gmail.com

Mestre em Gestão. Faculdade de Economia da Universidade de Coimbra.

\section{Arnaldo Coelho coelho1963@hotmail.com PHD em Gestão. Professor e coordenador dos cursos de dou- toramento e MBA da Universi- dade de Coimbra - Portugal. \\ Cristela Maia Bairrada cristela.bairrada@gmail.com Doutora em Gestão. Professora na Faculdade de Economia da Universidade de Coimbra e no Instituto Superior de Contabilidade e Administração da Universidade de Aveiro - Portugal.} a uma melhor gestão da autenticidade de marca são fornecidas, sugerindo uma aplicação adequada a outros relevantes produtos portugueses.

Palavras-chave: Marcas. Autenticidade de Marca.Vinho do Porto. Brand Equity.

\section{INTRODUÇÃO}

Esta investigação aborda um dos produtos mais representativos da economia portuguesa dos últimos três séculos: o vinho do Porto. Parte do que se observa, isto é, a prevalência de um pequeno conjunto de marcas, está relacionado ao o fato de que "os consumidores buscam marcas que são relevantes, originais e genuínas: eles procuram cada vez mais pela autenticidade de marca." (MORHART et al., 2014, p. 200). Mais do que isso, a autenticidade de marca ajuda a estimular o crescimento das empresas em mercados concorrenciais (EGGERS et al., 2013, p. 346). Nesse sentido, 
parece-nos factível vincular a autenticidade de marca como uma variável propulsora do Brand Equity: "autenticidade contém elementos intrínsecos ao produto, processo produtivo e/ ou ligações ao lugar e ao período histórico, e elementos subjetivos criados pelos executivos, pelos consumidores e pelas outras partes interessadas." (BEVERLAND, 2005, p. 1008). Nessa perpectiva, este trabalho de investigação tem como objetivo estudar o papel da autenticidade de marca percebida nas marcas de vinho do Porto e como esta ajuda a promover o Brand Equity. O presente trabalho de investigação será constituído por 5 tópicos fundamentais: revisão da literatura, modelo e hipóteses, metodologia, resultados e conclusões.

\section{REVISÃO DA LITERATURA}

\subsection{AUTENTICIDADE DA MARCA}

Uma das principais definições de marca é a proposta pela Associação Americana de Marketing (AMA - American Marketing Association), que a estabelece como "nome, termo, design, símbolo ou qualquer característica que identifica o produto ou serviço de um determinado vendedor como distinção de outros vendedores." A marca como "a experiência total oferecida por uma organização para seus colaboradores, clientes e outros, como combinação impetuosa e distintiva de promessas intangíveis e características e benefícios tangíveis." (ALLEN; SIMMONS, 2003, p. 113).

Muitos especialistas de marketing postulam a estreita relação entre os componentes racionais e emocionais da marca (BATRA; AHUVIA; BAGOZZI, 2012; CARROLL; AHUVIA, 2006; SUNG; KIM, 2010). Dessa forma, esses profissionais creem que "um bom posicionamento de marca deve conter pontos de diferenciação e pontos de convergência que apelam tanto a razão como a emoção." (KOTLER; KELLER, 2012, p. 290).

Sob essa perspectiva, uma marca "pode ser considerada como um conjunto de valores funcionais e emocionais que promete uma experiência única e bem-vinda." (CHRISTODOULIDES; CHERNATONY, 2010, p. 8). As marcas são parte do nosso dia a dia (ALBERT; MERUNKA; VALETTE-FLORENCE, 2008; MAXIAN et al., 2013). Uma marca pode ser definida como "um ativo que não tem existência física e cujo valor não pode ser determinado exatamente, a não ser no momento em que se torna objeto de uma transação comercial de compra e venda." (SEETHARAMAN; NADZIR; GUNALAN, 2001, p. 243). Outra definição consiste em considerar uma marca como um nome ou um símbolo - e os aspetos tangíveis e emocionais que lhe estão associados - tendo a intenção de identificar bens e serviços de um vendedor e de os diferenciar dos restantes concorrentes (SEETHARAMAN et al., 2001).

Entre os componentes emocionais da marca, "tanto acadêmicos como especialistas concordam com a importância da autenticidade no comportamento do consumidor e para a gestão de marcas." (MORHART et al., 2014, p. 200). Marcas percebidas como "autênticas e genuínas podem evocar confiança, afeição e grande lealdade." (KOTLER; KELLER, 2012, p. 290).

A autenticidade de marca é um conceito relativamente novo, "não há um consenso em uma definição geral para a autenticidade de marca assim como não há um acordo quanto a estrutura de suas dimensões." (BRUHN et al., 2012, p. 567). A autenticidade da marca "parece estar relacionada e associada aos seguintes termos: estabilidade, resistência, consistência, particularidade, individualidade, confiabilidade, credibilidade, cumpridor de promessas, genuidade, e realismo." (BRUHN et al., 2012, p. 568). A despeito da multiplicidade de termos e interpretações relacionadas a esse conceito, "fundamentalmente o que é consistente na literatura é que a autenticidade agrega o que é genuíno, real e/ ou verdadeiro." (BEVERLAND; FARRELLY, 2010, p. 839). Nesta investigação, utilizaremos o conceito de autenticidade de marca como:

A extensão pela qual os consumidores percebem uma marca como fiéis à si 
mesmas (continuidade), verdadeiras aos seus consumidores (credibilidade), motivadas em se importar e se responsabilizarem (integridade), e capazes de apoirem os consumidores a serem verdadeiros a eles mesmos (simbolismo) (MORHART et al., 2014, p. 203).

O conceito de Continuidade está relacionado à definição de patrimônio ou legado, em que, "ao longo do tempo, as pessoas reconhecem e esperam que a empresa irá manter seu nível de comprometimento." (URDE; GREYSER; BALMER, 2007, p. 9).

A dimensão de Credibilidade guarda semelhanças com a fiabilidade da marca, isto é, "de que a marca tem a capacidade (a especialização) e a boa vontade (a confiabilidade) em continuamente prover aquilo que foi prometido." (ERDEM; SWAIT, 2004, p. 192).

A dimensão da Integridade relaciona a responsabilidade da marca em "ser verdadeira a um conjunto de valores morais." (BEVERLAND; FARRELLY, 2010, p. 844). A percepção da Integridade é "baseada na virtude refletida nos propósitos da marca e nos valores que ela comunica." (MORHART et al., 2014, p. 202).

O conceito de Simbolismo reflete o potencial da marca de representar "pessoas, culturas, tempo e lugar, e comunidade." (BEVERLAND; FARRELLY, 2010, p. 844). Tal atributo se relaciona ao comportamento do consumidor, pois este desenvolve "um senso de unidade com a marca, estabelecendo vínculos cognitivos que ligam a marca com eles próprios." (PARK et al., 2010, p. 2).

A importância do atributo da autenticidade de marca reside no fato de que "os consumidores valorizam cada vez mais a autenticidade em um mundo onde a produção maciça de artefatos provoca o questionamento da plausibilidade do valor." (ROSE; WOOD, 2005, p. 286). No caso das companhias vinícolas, "parecer autêntico é crucial para reforçar sua condição, praticar o preço-prêmio e distanciar-se de competidores." (BEVERLAND, 2005, p. 1003). Um alto nível desses atributos, associa- dos a uma marca julgada como autêntica pelos consumidores, proporciona uma percepção de uma marca que se dedicada ao negócio e a estes. Quer dizer, teremos como consequente à dimensão de autenticidade de marca o Passa-palavra Positivo uma vez, nessa situação, os "consumidores são mais propensos a se dedicarem com reciprocidade positiva para a marca." (MORHART et al., 2014, p. 207).

\subsection{BRAND EQUITY}

A análise do Brand Equity é considerada pelos diversos autores sob duas vertentes: a primeira perspectiva discute "o valor financeiro que o Brand Equity proporciona para o negócio, sendo comumente referido como Firm Based Brand Equity (FBBE)." (CHRISTODOULIDES; CHERNATONY, 2010, p. 6). A outra proposta é a abordagem Customer-Based Brand Equity (CBBE), definida como o "efeito diferencial do conhecimento de marca na resposta do consumidor ao marketing daquela marca." (KELLER, 2013, p. 69). O modelo proposto por Yoo, Donthu e Lee (2000) explora as relações entre os Elementos do Marketing mix e a criação do Brand Equity, compreendidos pela Qualidade Percebida, Lealdade de Marca e Consciência da Marca / Associações.

A importância do Brand Equity reflete-se como "a medida da intenção de compra ou a preferência por uma determinada marca, em contrapartida a uma outra qualquer." (YOO; DONTHU; LEE, 2000, p. 196). Um segundo modelo que analisa o Brand Equity na perspectiva dos consumidores é o modelo Brand Equity Ten de Aaker. "Esta designação deve-se a um conjunto de dez variáveis que permitem medir o capital de marca ao longo de cinco dimensões." (DIOGO, 2008, p. 188). As quatro primeiras dimensões representam "as percepções da marca [...] pelas variáveis lealdade, qualidade percebida, associações de marca e notoriedade." (AAKER, 1996, p. 317). A quinta categoria "reflecte o comportamento e o desempenho da empresa através de informações obtidas pelo mercado." (DIOGO, 2008, p. 189). 


\section{MODELO E HIPÓTESES}

\subsection{MODELO}

O modelo conceptual proposto (Figura 8) foi desenvolvido e adaptado a partir dos estudos realizados por Yoo, Donthu e Lee (2000) e Morhart et al. (2014).

No caso deste trabalho de investigação, consideramos 5 antecedentes da autenticidade da marca e, como consequência, as diferentes dimensões do Brand Equity. Também, nesse modelo, consideramos um conjunto de variáveis moderadoras.

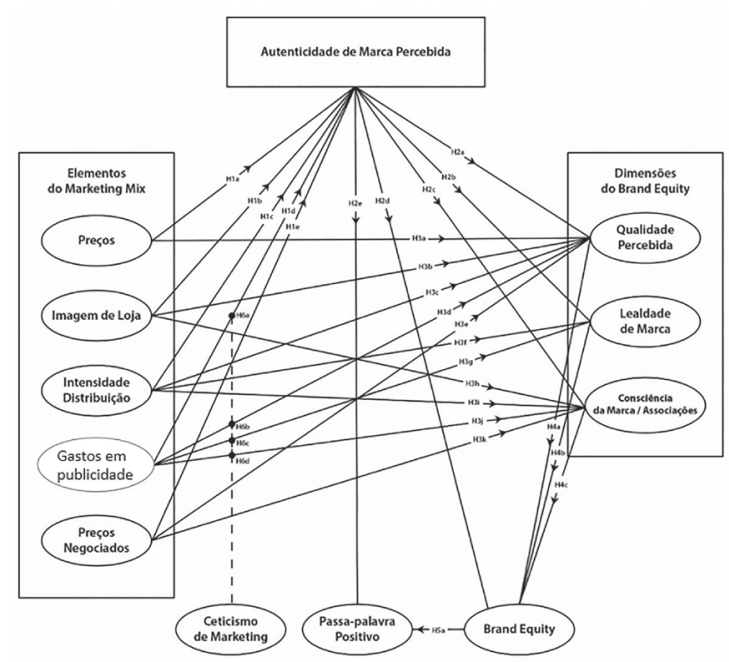

Figura 1- Modelo conceptual

Fonte: adptado de Yoo, Donthu e Lee (2000) e Morhart et al. (2014).

\subsection{HIPÓTESES}

\subsubsection{Determinantes da autenticidade da marca}

Segundo Yoo, Donthu, Lee (2000), existem cinco elementos da estratégia de Marketing: Preços, Imagem da Loja, Intensidade de Distribuição, Gastos em Propaganda e a frequência de Promoções por Preços. Este estudo concluiu que, apesar de os "fatores selecionados não abragerem todos os esforços de Marketing, são suficientemente representativos para demonstrar as relações entre os Elementos do
Marketing mix e a formação do Brand Equity." (YOO; DONTHU; LEE, 2000, p. 198).

Contudo, encontramos na literatura um estreito relacionamento entre a autenticidade da marca e os Elementos do Marketing mix, que comumente busca reforçar "uma imagem de autenticidade por seu componente histórico, pela tradição, localidade e pela linhagem de uma marca em suas atividades promocionais." (MORHART et al., 2014, p. 207).

Seguindo esses pressupostos, como hipóteses de antecedentes da dimensão de Autenticidade de Marca, temos:

H1a: Há uma relação positiva entre Preços altos das marcas de vinho do Porto e a Autenticidade de Marca percebida nestas.

H1b: Há uma relação positiva entre a Imagem de Loja onde são vendidas as marcas de vinho do Porto e a Autenticidade de Marca percebida nestas.

H1c: Há uma relação positiva entre a Intensidade de Distribuição das marcas de vinho do Porto e a Autenticidade de Marca percebida nestas.

H1d: Há uma relação positiva entre os Gastos em Propaganda das marcas de vinho do Porto e a Autenticidade de Marca percebida nestas.

H1e: Há uma relação negativa entre os Preços Negociados nas lojas onde são vendidas as marcas de vinho do Porto e a Autenticidade de Marca percebida nestas.

\subsubsection{Consequências da autenticidade da marca}

\subsubsection{A autenticidade e o Brand equity}

Apesar de não existir uma referência na literatura entre a Autenticidade de Marca e as Dimensões do Brand Equity, percebe-se um estreito relacionamento entre cada um desses conceitos.

A Qualidade percebida guarda semelhança com o conceito de Credibilidade de marca, uma vez que "fabricantes que posicionam sua marca como de alta qualidade são propensos a serem mais cuidados na escolha de retalhistas, [...] sendo que lojas com forte imagem de loja e 
uma reputação para operações de excelência são preferidas." (FRAZIER; LASSAR, 1996, p. 40).

Relativamente ao conceito de Lealdade, marcas percebidas como "autênticas e genuínas podem evocar confiança, afeição e grande lealdade." (KOTLER; KELLER, 2012, p. 290).

Os consumidores desenvolvem um "conhecimento da marca através de experiências diretas (isto é, ao fazer uso do serviço ou produto) e experiência indiretas (isto é, através de propaganda ou materiais de divulgação) de certa marca." (LU; GURSOY; LU, 2015, p. 38). De acordo com essa lógica, a percepção da autenticidade pelo consumidor nessas experiências pode ser um contributo significativo para a notoriedade da marca.

A gestão de marcas enfatiza o conceito de continuidade e a conexão da empresa com o seu ambiente externo. Por sua vez, "ativos baseados no mercado permitem à firma suprir o valor da marca percebida, Brand Equity e aumentar a sua reputação." (ABIMBOLA; KOCAK, 2007, p. 422). Nesse contexto, pode-se perceber o importante papel das percepções do consumidor relativamente à autenticidade para a criação do Brand Equity.

Seguindo esses pressupostos, como hipóteses de impacto/consequentes da dimensão de Autenticidade de Marca, temos:

H2a: Há uma relação positiva entre a Autenticidade percebida nas marcas de vinho do Porto e a Qualidade percebida nestas.

H2b: Há uma relação positiva entre a Autenticidade percebida nas marcas de vinho do Porto e a Lealdade de Marca destas.

H2c: Há uma relação positiva entre a Autenticidade percebida nas marcas de vinho do Porto e a Consciência / Associações destas.

H2d: Há uma relação positiva entre a Autenticidade percebida nas marcas de vinho do Porto e o Brand Equity.

\subsubsection{A autenticidade e o Passa-palavra Positivo}

Relativamente ao constructo de Passa-palavra Positivo, "os consumidores tendem a retribuir a dedicação recebida através de atitudes positivas para a marca." (MORHART et al., 2014, p. 207).

De acordo com Moulard, Raggio e Folse (2016) e Fritz , Schoenmueller e Bruhn (2017), uma vez que a autenticidade da marca está ligada ao conceito de qualidade, podemos concluir que, perante essa ligação, também o consumidor estará disposto a falar bem de produtos e marcas que ele perceciona como tudo qualidade.

H2e: Há uma relação positiva entre a Autenticidade percebida nas marcas de vinho do Porto e o Passa-palavra Positivo.

\subsubsection{As dimensões do Brand Equity}

De acordo com a literatura de referência, a adoção de ações representativas da promoção comercial, como preços, imagem de loja, intensidade de distribuição, gastos em propaganda e preços negociados, apesar de "não abrangerem o pleno domínio dos esforços de marketing, são suficientemente representativos para demonstrar as relações destes com a formação do Brand Equity." (YOO; DONTHU; LEE, 2000, p. 198).

Seguindo esses pressupostos, relativamente às hipóteses de antecedentes das Dimensões do Brand Equity, temos:

H3a: Há uma relação positiva entre Preços altos das marcas de vinho do Porto e a Qualidade Percebida nestas.

H3b: Há uma relação positiva entre a Imagem de Loja onde são vendidas as marcas de vinho do Porto e a Qualidade Percebida nestas.

H3c: Há uma relação positiva entre a Intensidade de Distribuição das marcas de vinho do Porto e a Qualidade Percebida nestas.

H3d: Há uma relação positiva entre os Gastos em Propaganda das marcas de Vinho do Porto e a Qualidade Percebida nestas.

H3e: Há uma relação negativa entre os Preços Negociados nas lojas onde são vendidas as marcas de vinho do Porto e a Qualidade Percebida nestas.

H3f: Há uma relação positiva entre a Intensidade de Distribuição das marcas de vinho do Porto e a Lealdade destas. 
H3g: Há uma relação positiva entre os Gastos em Propaganda das marcas de vinho do Porto e a Lealdade destas.

H3h: Há uma relação positiva entre a Imagem de Loja onde são vendidas as marcas de vinho do Porto e a Consciência da Marca / Associações destas.

H3i: Há uma relação positiva entre a Intensidade de Distribuição das marcas de vinho do Porto e a Consciência da Marca / Associações destas.

H3j: Há uma relação positiva entre os Gastos em Propaganda das marcas de vinho do Porto e a Consciência da Marca / Associações destas.

H3k: Há uma relação negativa entre os Preços Negociados nas lojas onde são vendidas as marcas de vinho do Porto e a Consciência da Marca / Associações destas.

De acordo com os resultados apurados nos estudos de referência, uma alta dotação de Brand Equity "indica que os consumidores têm várias associações positivas e fortes perante à marca, percebem-na como de alta qualidade e são lhes leais." (YOO; DONTHU; LEE, 2000, p. 197).

Seguindo esses pressupostos, como hipóteses de impacto/consequentes no Brand Equity, temos:

H4a: Há uma relação positiva entre a Qualidade Percebida nas marcas de vinho do Porto e o Brand Equity.

H4b: Há uma relação positiva entre a Lealdade de Marca dos vinhos do Porto e o Brand Equity.

H4c: Há uma relação positiva entre a Consciência / Associações das marcas de vinho do Porto e o Brand Equity.

\subsubsection{O Brand Equity e o Passa-palavra Positivo}

A notoriedade de uma marca, um dos componentes do Brand Equity, "reflecte não só a intensidade com que a marca está presente na mente do consumidor, como também reflecte o resultado, bom ou mau, da experiência de contacto que o consumidor teve com a marca." (DIOGO, 2008, p. 94).
A pesquisa em marketing geralmente suporta que "o passa-palavra mostra-se capaz de influenciar uma variedade de condições: notoriedade, expectativas, percepções, atitudes, intenções comportamentais e comportamento." (BUTTLE, 1998, p. 242). Nesse sentido, parece existir uma relação significativa entre o Brand Equity e o Passa-palavra Positivo, uma vez que este "reflecte-se na formulação de percepções positivas face à marca, bem como em atitudes e comportamentos favoráveis à recomendação, utilização e consumo." (DIOGO, 2008, p. 357).

Seguindo esses pressupostos, como hipóteses de impacto/consequentes do Brand Equity, temos:

H5a: Há uma relação positiva entre o Brand Equity nas marcas de vinho do Porto e o Passa-palavra Positivo.

\subsubsection{O efeito moderador do ceticismo de marketing}

A intensidade de alguns efeitos da promoção comercial é dependente das crenças individuais, já que "a personalidade do consumidor e sua experiência de vida modelam a crença deles quanto à publicidade de maneira geral." (OBERMILLER; SPANGENBERG, 1998, p. 167).

Nesse contexto, "consumidores considerados como de maior ceticismo desenvolvem estratégias para lidar com técnicas influenciadoras e geralmente respondem menos positivamente às comunicações de marketing." (MORHART et al., 2014, p. 207).

Seguindo esses pressupostos, relativamente às hipóteses de efeitos moderadores da dimensão de Ceticismo de Marketing, temos:

H6a: Há um efeito moderador de Ceticismo de Marketing entre os Gastos em Publicidade das marcas de vinho do Porto e a Autenticidade de Marca percebida nestas.

H6b: Há um efeito moderador de Ceticismo de Marketing entre os Gastos em Publicidade das marcas de vinho do Porto e a Qualidade Percebida nestas.

H6c: Há um efeito moderador de 
Ceticismo de Marketing entre os Gastos em Publicidade das marcas de vinho do Porto e a Lealdade destas.

H6d: Há um efeito moderador de Ceticismo de Marketing entre os Gastos em Publicidade das marcas de vinho do Porto e a Consciência da Marca / Associações destas.

\section{METODOLOGIA}

\subsection{AMOSTRA E RECOLHA DE DADOS}

Este estudo foi operacionalizado baseado em dados recolhidos de forma transversal, junto de uma amostra de 261 indivíduos de nacionalidade portuguesa $(66,7 \%)$ e estrangeira $(33,3 \%)$, com recurso a um questionário estruturado. Os respondentes são 141 pessoas $(54,0 \%)$ do sexo masculino e $120(46,0 \%)$, do sexo feminino, $73 \%$ dos quais, solteiros. Quanto à idade, entre os 18 e os 24 anos foram recolhidos 128 inquéritos, o que perfazem $49,0 \%$ dos inquéritos totais, de 25 a 34 anos, 65 participantes, isto é, 24,9\% do total, dos 35 aos 44 anos, 34 respondentes (13\%) e com mais de 45 anos, 34 respondentes (13\%). 75\% dos respondentes vivem em agregados de até 3 pessoas e $70 \%$ são detentores de um diploma universitário. 158 (61\%) dos respondentes declararm ter rendimentos mensais até $1499 €, 53(20,3 \%)$ entre $1500 €$ e $2499 €$ e $50(19 \%)$ mais de $2500 € .197$ respondentes $(75,5 \%)$ apontaram ser consumidores ocasionais de vinhos ao passo que os restantes 64 (24.5\%) são consumidores regulares.

\subsection{MÉTRICAS}

As variáveis presentes neste estudo foram medidas com base em escalas testadas e publicadas em revistas de referência, traduzidas e adaptadas para o contexto do estudo. As métricas foram operacionalizadas por recurso a escalas de Likert de 7 pontos desde "discordo totalmente" até "concordo totalmente". O questionário foi objeto de um pré-teste junto de 20 respondentes e de 5 professores da área de marketing, para avaliar questões de compre- ensibilidade e rigor linguístico, assegurando a qualidade das respostas dos inquiridos.

Autenticidade da Marca: foi medida a partir da escala de Morhart et al. (2014, p. 202). A escala é composta de 4 dimensões, continuidade, credibilidade, integridade e simbolismo, em um total de 15 itens; Elementos do marketing-mix: foi medida a partir da escala de Yoo, Donthu e Lee (2000). A escala é composta de 5 dimensões, preço, imagem da loja, intensidade da distribuição, gastos em publicidade e preços negociados (ofertas), com um total de 15 itens; Brand equity: foi medida a partir da escala de Yoo, Donthu e Lee (2000). A escala é composta de 3 dimensões, qualidade percebida, lealdade e consciência/notoriedade da marca, utilizando um total de 15 itens; Overall brand equity: foi medida a partir da escala de Yoo, Donthu e Lee (2000). A escala é composta de 4 itens.

Passa-palavra Positivo: foi medida a partir da escala Morhart et al. (2014). A escala é medida usando 4 itens e Ceticismo de marketing: foi medida a partir da escala Morhart et al. (2014). A escala é medida usando 7 itens.

\subsection{MODELAGEM ESTATÍSTICA}

Foi realizada uma análise fatorial exploratória seguida de uma análise fatorial confirmatória, para "avaliar a qualidade do ajustamento do modelo de medidas teórico à estrutura correlacional observada entre as variáveis manifestas (itens)." (MARÔCO, 2014, p. 180). Foi utilizada a Modelagem de Equações Estruturais (SEM - Structural Equation Modelling) que pode ser descrita como uma "combinação das técnicas clássicas de Análise Fatorial (que define um modelo de medida que operacionaliza variáveis latentes ou constructos) e de Regressão Linear (que estabelece, no modelo estrutural, a relação entre as diferentes variáveis sob estudo)." (MARÔCO, 2014, p. 3-4).

O modelo de medidas apresentou níveis de ajustamento que podem ser considerados bons: $\chi 2 / d f=1,739$ TLI $=0,904 ; \mathrm{CFI}=0,918$; $\mathrm{IFI}=0,920$ e $\mathrm{RMSEA}=0,053$. 


\begin{tabular}{|c|c|c|c|c|c|c|c|c|c|c|c|c|c|}
\hline$\sum_{4}^{5}$ & 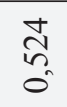 & $\begin{array}{l}n \\
n \\
n \\
0\end{array}$ & $\begin{array}{l}\text { ర్ర } \\
\text { ర్ } \\
0\end{array}$ & 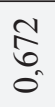 & $\frac{\hat{n}}{\hat{\sigma}}$ & $\begin{array}{l}1 \\
\infty \\
n \\
0 \\
0\end{array}$ & $\begin{array}{l}\stackrel{0}{2} \\
\tilde{n} \\
0\end{array}$ & $\frac{n}{n}$ & 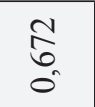 & 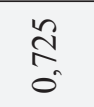 & $\begin{array}{l}\stackrel{Y}{*} \\
\stackrel{n}{n} \\
\sigma^{\prime}\end{array}$ & $\underset{0}{\pi}$ & $\begin{array}{l}\hat{6} \\
0 \\
0 \\
0\end{array}$ \\
\hline$\underline{U}$ & $\begin{array}{l}\stackrel{0}{0} \\
0 \\
0\end{array}$ & $\begin{array}{l}8 \\
\infty \\
0 \\
0\end{array}$ & 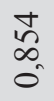 & $\begin{array}{l}8 \\
\infty \\
\infty \\
0\end{array}$ & $\begin{array}{l}n \\
\infty \\
0\end{array}$ & $\begin{array}{l}\text { I } \\
\infty \\
0 \\
0\end{array}$ & $\frac{\hat{a}}{0}$ & $\frac{a}{\frac{2}{0}}$ & $\begin{array}{l}\infty \\
\infty \\
\infty \\
0\end{array}$ & $\frac{m}{\sigma}$ & $\frac{a}{\hat{0}}$ & $\begin{array}{l}\hat{2} \\
\infty \\
\infty \\
0\end{array}$ & $\begin{array}{l}+ \\
\text { D. } \\
0 \\
0\end{array}$ \\
\hline$\frac{m}{x}$ & & & & & & & & & & & & & 周 \\
\hline$\frac{N}{x}$ & & & & & & & & & & & & $\stackrel{\bar{\delta}}{\infty}$ & $\begin{array}{l}\vec{J} \\
\underbrace{}_{0}\end{array}$ \\
\hline$\overline{\bar{x}}$ & & & & & & & & & & & 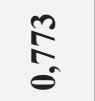 & $\begin{array}{l}\hat{n} \\
\hat{0}\end{array}$ & $\begin{array}{l}\infty \\
\infty \\
0 \\
0\end{array}$ \\
\hline$\stackrel{\theta}{x}$ & & & & & & & & & & ब․ & \begin{tabular}{l}
\multirow{f}{*}{} \\
足 \\
0
\end{tabular} & $\begin{array}{l}2 \\
\infty \\
n \\
0\end{array}$ & \begin{tabular}{l}
$\infty$ \\
\multirow{+}{*}{} \\
$0^{2}$ \\
0
\end{tabular} \\
\hline$\ddot{x}$ & & & & & & & & & 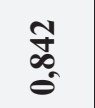 & $\begin{array}{l}\overrightarrow{0} \\
\hat{0} \\
0\end{array}$ & $\begin{array}{l}\text { त̃ } \\
\text { त̂ }\end{array}$ & Oి & $\frac{n}{n}$ \\
\hline$\stackrel{\infty}{x}$ & & & & & & & & $\frac{g}{\tilde{T}}$ & $\begin{array}{l}n \\
\hat{\sigma} \\
0\end{array}$ & $\begin{array}{l}0 \\
0 \\
0\end{array}$ & $\begin{array}{l}\infty \\
\infty \\
0 \\
0\end{array}$ & $\begin{array}{l}\text { ণ̃ } \\
\text { Oे } \\
0\end{array}$ & $\frac{a}{\dot{J}}$ \\
\hline $\bar{x}$ & & & & & & & 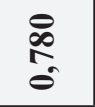 & $\begin{array}{l}\text { J } \\
\text { ñ. } \\
0\end{array}$ & 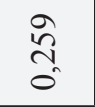 & $\frac{m}{\sigma}$ & $\frac{\stackrel{Y}{ \pm}}{0}$ & 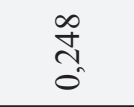 & $\begin{array}{l}\infty \\
\text { స్ } \\
0\end{array}$ \\
\hline$\ddot{x}$ & & & & & & $\begin{array}{l}\stackrel{2}{\infty} \\
\stackrel{\theta}{0}\end{array}$ & $\begin{array}{l}\text { ลे } \\
\text { กิ }\end{array}$ & 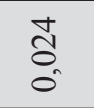 & $\hat{\sigma}$ & $\begin{array}{l}\nabla \\
n \\
0\end{array}$ & $\begin{array}{l}\text { నू } \\
\text { సे }\end{array}$ & $\stackrel{\text { ॄे }}{\stackrel{0}{0}}$ & $\begin{array}{l}\hat{6} \\
\text { no } \\
0\end{array}$ \\
\hline$\ddot{x}$ & & & & & $\begin{array}{l}\infty \\
\infty \\
\infty \\
\infty \\
0\end{array}$ & $\frac{\dot{J}}{\nabla_{0}}$ & $\frac{\infty}{0}$ & 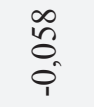 & 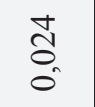 & $\begin{array}{l}\text { సु. } \\
\text { ర్ }\end{array}$ & 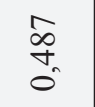 & $\frac{\infty}{n}$ & $\begin{array}{l}\text { d̆ } \\
\text { ó }\end{array}$ \\
\hline$\ddot{x}$ & & & & $\begin{array}{l}0 \\
\infty \\
\infty \\
0 \\
0\end{array}$ & $\frac{a}{\vec{\sigma}_{0}}$ & $\begin{array}{l}\text { J } \\
\text { m } \\
0\end{array}$ & त̂ & $\frac{\infty}{0}$ & $\begin{array}{l}\text { ¿ू. } \\
\text { तू }\end{array}$ & 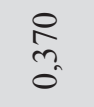 & $\begin{array}{l}\text { రి } \\
\text { nn. } \\
0\end{array}$ & $\begin{array}{l}0 \\
\text { m. } \\
\text { o. }\end{array}$ & $\begin{array}{l}\infty \\
n \\
n \\
0\end{array}$ \\
\hline$\ddot{x}$ & & & \begin{tabular}{l}
$\infty$ \\
\multirow{\infty}{*}{} \\
0 \\
0
\end{tabular} & $\begin{array}{l}\text { ra } \\
\infty \\
2 \\
0\end{array}$ & $\begin{array}{l}\infty \\
\stackrel{9}{+} \\
\stackrel{0}{0}\end{array}$ & 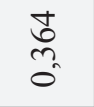 & $\frac{2}{0}$ & $\frac{\infty}{\frac{\infty}{0}}$ & $\begin{array}{l}\text { ஸे } \\
\text { On }\end{array}$ & $\begin{array}{l}\text { ro } \\
\stackrel{+}{+} \\
0\end{array}$ & $\begin{array}{l}\stackrel{ \pm}{2} \\
\text { ñ } \\
0\end{array}$ & $\begin{array}{l}\infty \\
\text { ஸे } \\
\text { o. }\end{array}$ & $\begin{array}{l}\text { के } \\
\text { ?. } \\
0\end{array}$ \\
\hline$\tilde{x}$ & & $\stackrel{8}{\stackrel{\circ}{\circ}}$ & $\begin{array}{l}\text { Oे } \\
\text { O. }\end{array}$ & 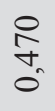 & तु & $\underset{m}{\tilde{m}}$ & 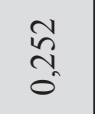 & $\begin{array}{l}\tilde{2} \\
0 \\
0 \\
1\end{array}$ & $\begin{array}{l}\overline{8} \\
8\end{array}$ & 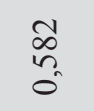 & $\begin{array}{l}\infty \\
\infty \\
\tilde{m}^{2}\end{array}$ & \begin{tabular}{l}
$\hat{\delta}$ \\
\multirow{0}{*}{}
\end{tabular} & $\begin{array}{l}\hat{\sigma} \\
\text { ஸे } \\
0\end{array}$ \\
\hline $\bar{x}$ & $\frac{\infty}{\stackrel{\infty}{n}}$ & $\begin{array}{l}\stackrel{2}{2} \\
\text { م) }\end{array}$ & $\begin{array}{l}\text { J } \\
\text { : } \\
0\end{array}$ & $\underset{n}{\stackrel{N}{n}}$ & 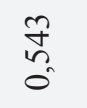 & $\begin{array}{l}n \\
\tilde{n} \\
\hat{\sigma}\end{array}$ & $\begin{array}{l}\hat{\sigma} \\
\text { Nh} \\
0\end{array}$ & $\stackrel{n}{0}$ & $\begin{array}{l}N \\
0 \\
0 \\
i\end{array}$ & $\begin{array}{l}\infty \\
\stackrel{2}{n} \\
0\end{array}$ & $\begin{array}{l}\vec{J} \\
\text { m. } \\
0\end{array}$ & $\begin{array}{l}+ \\
\stackrel{\infty}{+} \\
0\end{array}$ & $\underset{\hat{n}}{\hat{n}}$ \\
\hline$\hat{\mathrm{t}}$ & \& & $\stackrel{\text { Oे }}{0}$ & $\begin{array}{l}8 \\
\stackrel{6}{=}\end{array}$ & $\stackrel{n}{n}$ & $\begin{array}{l}\stackrel{1}{\infty} \\
=\end{array}$ & $\stackrel{\infty}{=}$ & 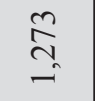 & 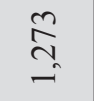 & $\underset{\sim}{\vec{f}}$ & $\stackrel{\Xi}{\stackrel{\Xi}{=}}$ & $\stackrel{n}{n}$ & $\stackrel{n}{2}$ & $\underset{\sim}{\tilde{\sigma}}$ \\
\hline & 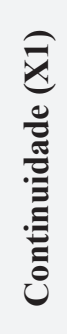 & 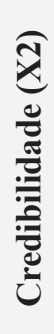 & 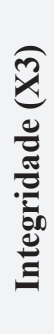 & 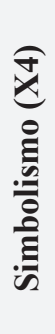 & 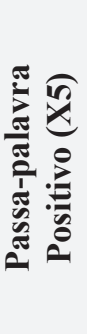 & 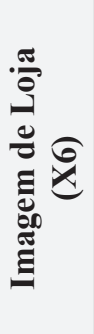 & 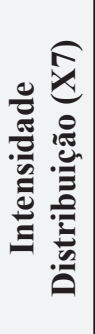 & 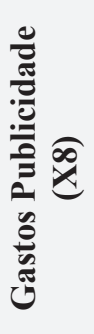 & 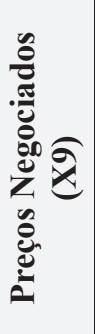 & 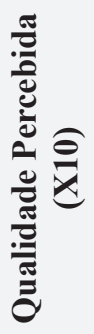 & 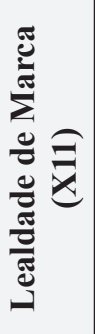 & 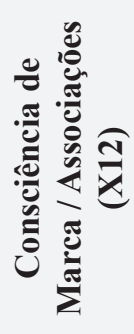 & 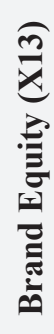 \\
\hline
\end{tabular}


Os valores de AVE são todos superiores a 0.5 , e os valores de CR são superiores a 0.7 , o que mostra que as medidas utilizadas apresentam validade compósita. A validade discriminante afere-se pelo fato de a soma dos quadrados das correlações ser inferior ao valor do AVE das variáveis correspondentes, e, no caso das excepções, o valor de VIF foi sempre inferior a 5, o que exclui qualquer problema de multicolinearidade (MARÔCO, 2014, p. 66).

\section{RESULTADOS}

\subsection{TESTE DE HIPÓTESES}

No caso do modelo estrutural, o valor apurado no Teste $\chi^{2}$ foi de 1 291,947, com um p de significância igual a 0,000, o que denota um bom ajustamento. Ao calcular a razão deste indicador com os graus de liberdade apurados $(\mathrm{gl}=707)$, obtemos o Índice $\chi^{2 / g l}$ de 1,827 , valor este considerado bom. Apesar do Índice de Qualidade de Ajuste $(\mathrm{GFI}=0,796)$ não ter atingido os valores satisfatórios, está bem próximo do valor considerado como tal (a partir de 0,800). O Índice de Tucker-Lewis (TLI $=0,892)$ e o Índice de Ajuste Normado (NFI $=0,809)$ resultaram em valores considerados como sofríveis (aceitáveis). É de se notar que eles estão próximo do valor considerado como bom, isto é, resultados de ajustamento a partir de 0,900 . No que tange aos outros indicadores da análise do ajuste incremental, a saber: o Índice de Ajuste Comparativo (CFI = 0,902) e o Índice de Ajuste Incremental (IFI = 0,903), os valores resultantes são considerados bons, o que garante a qualidade do ajustamento do modelo. Por fim, os valores resultantes para a estatística Raiz do Erro Quadrático Médio de Aproximação (RMSEA $=0,056)$ indicam um bom ajustamento do modelo.

De uma forma geral, confirmamos uma boa qualidade de ajustamento do modelo no seu conjunto, sobretudo levando em consideração o número de variáveis e os paramêtros a estudar.

Em seguida, apresentam-se os principais resultados desta investigação.
Tabela 1 - Resumo do teste de hipóteses

\begin{tabular}{|c|c|c|c|}
\hline \multicolumn{2}{|c|}{ Hipóteses } & SRW & $\mathbf{P}$ \\
\hline H1a & $\mathrm{PR} \rightarrow \operatorname{AUT}(+)$ & - & - \\
\hline $\mathrm{H} 1 \mathrm{~b}$ & $\mathrm{IM} \rightarrow \operatorname{AUT}(+)$ & 0,439 & $* * *$ \\
\hline $\mathrm{H} 1 \mathrm{c}$ & $\mathrm{ID} \rightarrow \mathrm{AUT}(+)$ & 0,153 & $*$ \\
\hline H1d & $\mathrm{GP} \rightarrow \mathrm{AUT}(+)$ & $-0,041$ & $\mathrm{p}>0,05$ \\
\hline H1e & $\mathrm{PN} \rightarrow \mathrm{AUT}(-)$ & 0,066 & $\mathrm{p}>0,05$ \\
\hline $\mathrm{H} 2 \mathrm{a}$ & $\mathrm{AUT} \rightarrow \mathrm{QP}(+)$ & 0,685 & $* * *$ \\
\hline $\mathrm{H} 2 \mathrm{~b}$ & $\mathrm{AUT} \rightarrow \mathrm{LM}(+)$ & 0,612 & $* * *$ \\
\hline $\mathrm{H} 2 \mathrm{c}$ & $\mathrm{AUT} \rightarrow \mathrm{CM}(+)$ & 0,554 & $* * *$ \\
\hline $\mathrm{H} 2 \mathrm{~d}$ & $\mathrm{AUT} \rightarrow \mathrm{BE}(+)$ & $-0,046$ & $\mathrm{p}>0,05$ \\
\hline $\mathrm{H} 2 \mathrm{e}$ & $\mathrm{AUT} \rightarrow \mathrm{PP}(+)$ & 0,661 & $* * *$ \\
\hline $\mathrm{H} 3 \mathrm{a}$ & $\mathrm{PR} \rightarrow \mathrm{QP}(+)$ & - & - \\
\hline $\mathrm{H} 3 \mathrm{~b}$ & $\mathrm{IM} \rightarrow \mathrm{QP}(+)$ & 0,223 & $* * *$ \\
\hline $\mathrm{H} 3 \mathrm{c}$ & $\mathrm{ID} \rightarrow \mathrm{QP}(+)$ & $-0,079$ & $\mathrm{p}>0,05$ \\
\hline $\mathrm{H} 3 \mathrm{~d}$ & $\mathrm{GP} \rightarrow \mathrm{QP}(+)$ & 0,149 & $*$ \\
\hline $\mathrm{H} 3 \mathrm{e}$ & $\mathrm{PN} \rightarrow \mathrm{QP}(-)$ & $-0,216$ & $* * *$ \\
\hline $\mathrm{H} 3 \mathrm{f}$ & $\mathrm{ID} \rightarrow \mathrm{LM}(+)$ & $-0,061$ & $\mathrm{p}>0,05$ \\
\hline $\mathrm{H} 3 \mathrm{~g}$ & $\mathrm{GP} \rightarrow \mathrm{LM}(+)$ & 0,189 & $* * *$ \\
\hline $\mathrm{H} 3 \mathrm{~h}$ & $\mathrm{IM} \rightarrow \mathrm{CM}(+)$ & 0,179 & $* * *$ \\
\hline $\mathrm{H} 3 \mathrm{i}$ & $\mathrm{ID} \rightarrow \mathrm{CM}(+)$ & 0,023 & $\mathrm{p}>0,05$ \\
\hline $\mathrm{H} 3 \mathrm{j}$ & $\mathrm{GP} \rightarrow \mathrm{CM}(+)$ & 0,199 & $*$ \\
\hline $\mathrm{H} 3 \mathrm{k}$ & $\mathrm{PN} \rightarrow \mathrm{CM}(-)$ & $-0,197$ & * \\
\hline $\mathrm{H} 4 \mathrm{a}$ & $\mathrm{QP} \rightarrow \mathrm{BE}(+)$ & 0,215 & * \\
\hline $\mathrm{H} 4 \mathrm{~b}$ & $\mathrm{LM} \rightarrow \mathrm{BE}(+)$ & 0,691 & $* * *$ \\
\hline $\mathrm{H} 4 \mathrm{c}$ & $\mathrm{CM} \rightarrow \mathrm{BE}(+)$ & 0,025 & $\mathrm{p}>0,05$ \\
\hline $\mathrm{H} 5 \mathrm{a}$ & $\mathrm{BE} \rightarrow \mathrm{PP}(+)$ & 0,132 & * \\
\hline
\end{tabular}

Fonte: resultados obtidos pelo processamento dos dados (IBM SPSS Amos).

Legenda: * $0,01<\mathrm{p}<0,05 ; * * * \mathrm{p}<0,01$ 
Levando em consideração as hipóteses de antecedentes da dimensão de Autenticidade de Marca, percebemos a existência de uma relação positiva entre a variável Imagem de Loja e a Autenticidade de Marca $(b=0,439 ; \mathrm{p}<$ $0,01)$ e a variável Intensidade de Distribuição e a Autenticidade de Marca ( $b=0,153 ; p<0,05)$.

As variáveis Gastos em Publicidade das marcas de vinho do Porto e os Preços Negociados nas lojas nas quais são comercializadas não têm impacto significativo na variável Autenticidade de Marca $(\mathrm{p}>0,05)$. Neste sentido, as hipóteses H1d e H1e não são sustentadas.

Relativamente às hipóteses de impacto/ consequentes da dimensão de Autenticidade de Marca, percebemos a existência de uma relação positiva entre ela e as variáveis Qualidade Percebida $(b=0,685)$, Lealdade de Marca $(b=0,612)$, Consciência da Marca / Associações $(\mathrm{b}=0,554)$ e Passa-palavra Positivo $(\mathrm{b}$ $=0,661)$, com um forte poder de explicação $(\mathrm{p}<0,01)$. A variável Autenticidade de Marca não tem impacto significativo na variável Brand Equity, sendo $\mathrm{p}>0,05$. Nesse sentido, a hipótese $\mathrm{H} 2 \mathrm{~d}$ não é suportada.

Os resultados apurados nos testes das hipóteses dos antecedentes das dimensões do Brand Equity apontam uma relação positiva entre as variáveis de Gastos em Publicidade com a variável Qualidade Percebida ( $\mathrm{b}=$ $0,149)$ e com a variável Consciência da Marca/ Associações $(b=0,199)$, com um bom poder de explicação $(\mathrm{p}<0,05)$. A variável Preços Negociados tem uma relação negativa sobre a variável Consciência da Marca/ Associações (b $=-0,197)$, com um bom poder de explicação $(p<0,05)$. A variável Gastos em Publicidade tem uma relação positiva com a variável Lealdade de Marca $(b=0,189)$, com um forte poder de explicação $(\mathrm{p}<0,01)$. A variável Imagem de Loja tem uma relação positiva com as variáveis Qualidade Percebida $(b=0,223)$ e com a variável Consciência da Marca / Associações $(b=0,179)$, com um forte poder de explicação $(\mathrm{p}<0,01)$. A variável Preços Negociados $(\mathrm{PN})$ tem uma relação negativa com a Qualidade Percebida $(b=-0,216)$, com um forte poder de explicação $(\mathrm{p}<0,01)$. A variável Intensidade Distribuição não tem impacto significativo nas variáveis Qualidade Percebida, Lealdade à Marca e Consciência da Marca / Associações, sendo $\mathrm{p}>0,05$. Nesse sentido, as hipóteses H3c, H3f e H3i não são sustentadas.

Relativamente às hipóteses de impacto das dimensões do Brand Equity, percebemos a existência de uma relação positiva entre a variável Lealdade à Marca e a variável Brand Equity $(b=0,691)$, com um forte poder de explicação $(\mathrm{p}<0,01)$. A variável Qualidade Percebida tem uma relação positiva com a o Brand Equity $(b=0,215)$, com um bom poder de explicação ( $\mathrm{p}<0,05)$. A variável Consciência da Marca / Associações não tem impacto significativo no Brand Equity $(\mathrm{p}>0,05)$. Nesse sentido, a hipótese $\mathrm{H} 4 \mathrm{c}$ não é suportada.

Os resultados apurados nos testes das hipóteses de impacto da dimensão do Brand Equity apontam para uma relação positiva entre a influência do Brand Equity e o Passa-palavra Positivo $(b=0,132 ; p<0,05)$.

\subsection{EFEITO MEDIADOR DA VARIÁVEL CETICISMO DE MARKETING}

Para o teste de hipóteses da variável moderadora Ceticismo de Marketing, realizamos a estruturação de dois grupos de análise: Consumidores mais céticos em relação às campanhas publicitárias e consumidores menos céticos em relação às campanhas publicitárias Da amostra de 261 indivíduos, o primeiro grupo resultou em 127 indivíduos (48,7\% do total) e o segundo grupo em 134 participantes (51,3\% do total).

Com base na análise de múltiplos grupos (Multiple-Group Analysis), foi possível obter os seguintes resultados expressos na tabela a seguir. 
Tabela 2 - Resumo do teste de hipóteses da variável moderadora

\begin{tabular}{|c|c|c|c|}
\hline \multicolumn{2}{|c|}{ Relacionamento das hipóteses } & \multirow[t]{2}{*}{ SRW } & \multirow[t]{2}{*}{$\mathbf{P}$} \\
\hline H6a & $\mathbf{G P} \rightarrow \mathbf{A U T}(+)$ & & \\
\hline \multicolumn{2}{|c|}{ Grupo 1 - Maior Ceticismo de Mkt } & $-0,096$ & $\mathrm{p}>0,05$ \\
\hline \multicolumn{2}{|c|}{ Grupo 2 - Menor Ceticismo de Mkt } & $-0,017$ & $\mathrm{p}>0,05$ \\
\hline H6b & $\mathbf{G P} \rightarrow \mathbf{Q P}(+)$ & & \\
\hline \multicolumn{2}{|c|}{ Grupo 1 - Maior Ceticismo de Mkt } & 0,090 & $\mathrm{p}>0,05$ \\
\hline \multicolumn{2}{|c|}{ Grupo 2 - Menor Ceticismo de Mkt } & 0,221 & $* * *$ \\
\hline H6c & $\mathbf{G P} \rightarrow \mathbf{L M}(+)$ & & \\
\hline \multicolumn{2}{|c|}{ Grupo 1 - Maior Ceticismo de Mkt } & 0,340 & $* * *$ \\
\hline \multicolumn{2}{|c|}{ Grupo 2 - Menor Ceticismo de Mkt } & 0,100 & $\mathrm{p}>0,05$ \\
\hline H6d & $\mathbf{G P} \rightarrow \mathbf{C M}(+)$ & & \\
\hline \multicolumn{2}{|c|}{ Grupo 1 - Maior Ceticismo de Mkt } & 0,431 & $\mathrm{p}>0,05$ \\
\hline \multicolumn{2}{|c|}{ Grupo 2 - Menor Ceticismo de Mkt } & 0,186 & $*$ \\
\hline
\end{tabular}

Fonte: resultados obtidos pelo processamento dos dados (IBM SPSS Amos)

Legenda: *0,01<p $<0,05 ; * * * \mathrm{p}<0,01$

$\mathrm{Na}$ análise do efeito moderador da variável Ceticismo de Marketing entre os Gastos em Publicidade das marcas de vinho do Porto e a Autenticidade de Marca, podemos perceber que, em nenhum dos grupos analisados, existe impacto significativo, sendo $\mathrm{p}>0,05$ para ambos os grupos. Nesse sentido, a hipótese H6a não é suportada.

Relativamente ao efeito moderador da variável Ceticismo de Marketing sobre os Gastos em Publicidade das marcas de vinho do Porto e a Qualidade Percebida nelas, percebemos que, para o primeiro grupo, isto é, para os indivíduos qualificados com maior Ceticismo de Marketing, não há impacto significativo $(\mathrm{p}>0,05)$. Para o grupo com menor Ceticismo de Marketing, percebemos a existência de uma relação positiva entre a variável Gastos em Publicidade e a variável Qualidade Percebida $(b=0,221)$, com um forte poder de explicação $(\mathrm{p}<0,01)$.

$\mathrm{Na}$ análise do efeito moderador da variável Ceticismo de Marketing entre os Gastos em Publicidade das marcas de vinho do Porto e a Lealdade, para o grupo com maior Ceticismo de Marketing, percebemos a existência de uma relação positiva entre as variáveis $(b=0,340 ; p<0,01)$. Para $o$ grupo com menor Ceticismo de Marketing, a variável Gastos em Publicidade não exerce impacto significativo na Lealdade ( $p>0,05)$.

Por fim, na análise do efeito moderador da variável Ceticismo de Marketing entre os Gastos em Publicidade das marcas de vinho do Porto e a Consciência da Marca / Associações à Marca, percebemos que, para o primeiro grupo, ou seja, para os indivíduos qualificados com maior Ceticismo de Marketing, não há impacto significativo $(\mathrm{p}>0,05)$. Para o grupo com menor Ceticismo de Marketing, percebemos a existência de uma relação positiva entre a variável Gastos em Publicidade e a Consciência da Marca / Associações $(b=0,186 ; p<0,05)$.

\subsection{DISCUSSÃO}

\subsubsection{Análise dos antecedentes da di- mensão de Autenticidade de Marca}

A variável Preços não foi validada na Análise Fatorial Confirmatória, de tal forma que não há como estabelecer uma relação entre ela com a 
dimensão de Autenticidade de Marca, não existindo evidências que suportem a hipótese H1a. A percepção do conceito de preço, por parte dos participantes do inquérito por questionário, sobretudo em relação a um produto singular como o vinho do Porto, foi provavelmente o grande obstáculo para esta análise. As marcas amplamente citadas nesta pesquisa comercializam seus produtos a preços que variam entre pouco mais de $5 €$ até no máximo $7 €$. Estes valores são relativamente baixos quando comparamos com os vinhos do Porto 10 anos, que atingem o preço médio de $18 €$ ou ainda aos vinhos premiados que podem chegar a valores próximos aos 300 $€$. Contudo, ao compararmos os preços citados com vinhos de outras regiões, por exemplo, da Península do Setúbal (preço médio de $4 €$ ), os preços dos vinhos do Porto passam a ser considerados como mais caros.

Dessa forma, a subjetividade presente no entendimento deste constructo inviabilizou a análise anteriormente proposta quanto à percepção de uma relação positiva entre os Preços altos das marcas de vinho do Porto e a Autenticidade de Marca percebida nelas. Relativamente às relações entre a Imagem de Loja e Intensidade de Distribuição com o constructo de Autenticidade de Marca (H1b e H1c, respectivamente), pode-se observar que os resultados corroboram as hipóteses elaboradas. Ainda que possa haver certa subjetividade no entendimento dos inquiridos para estes constructos, tendo em vista que, para eles, o principal espaço para compras deste produto é nas principais redes de supermercado, existe uma relação positiva para com a Autenticidade de Marca. Nesse sentido, Imagem de Loja e Intensidade de Distribuição são corrobados como antecedentes da dimensão Autenticidade de Marca.

No que diz respeito às ligações entre Gastos em Publicidade e Preços Negociados nas lojas nas quais são vendidas as marcas de vinho do Porto e a Autenticidade de Marca percebida nelas (H1d e H1e, respectivamente), os resultados não suportam as hipóteses propostas. Nesse ponto, é importante indicar que, tendo em vista o vinho do Porto ser uma bebida alcoólica, toda ação promocional é sujeita ao Código de Autorregulação da Comunicação Comercial em Matéria de Bebidas Alcoólicas - Vinhos e Bebidas Espirituosas. Dessa forma, esta comunicação não deve conter situações que induzam o seu consumo irresponsável ou ainda acrescentar-lhes um benefício ou a expectativa desse benefício, seja em dinheiro seja em género, se ele corporizar um incentivo ao consumo irresponsável.

\subsubsection{Análise dos consequentes da di- mensão de Autenticidade de Marca}

Seguidamente, apresentamos os resultados da análise feita aos consequentes da dimensão de Autenticidade de Marca. Foram investigados como consequentes da dimensão de Autenticidade de Marca os constructos: Qualidade Percebida, Lealdade de Marca, Consciência da Marca / Associações, Brand Equity e Passa-palavra Positivo.

Tendo em vista a recente literatura sobre a Autenticidade de Marca, poucas são as referências de consequentes para a dimensão que poderiam ser aplicados com propriedade no presente estudo. Dos indicados, apenas o Passa-palavra Positivo foi anteriormente estudado. Relativamente às relações existentes entre a Autenticidade de Marca e os constructos Qualidade Percebida, Lealdade de Marca e Consciência da Marca / Associações (H2a, H2b e H2c, respectivamente), pode-se observar que os resultados confirmam as hipóteses elaboradas.

Contudo, ao avaliar o impacto da Autenticidade de Marca sobre o constructo Brand Equity por si só, os resultados não são significativos, exibindo ainda uma relação negativa. No que diz respeito à relação existente entre Autenticidade de Marca e Passa-palavra Positivo (H2e), pode observar-se que os resultados coincidem com o esperado. De acordo com a literatura de referência, "os consumidores tendem a ser mais propensos a fazer depoimentos públicos relativamente à uma marca com atributos de autenticidade e advogar um passa-palavra positivo." (MORHART et al., 2014, p. 
207). Dessa forma, a hipótese H2e é suportada pelo presente estudo.

Nesse sentido, Qualidade Percebida, Lealdade de Marca, Consciência da Marca / Associações e Passa-palavra Positivo são corrobados como consequentes da dimensão $\mathrm{Au}-$ tenticidade de Marca.

\subsubsection{Análise dos antecedentes das Di- mensões do Brand Equity}

Fundamentado nos estudos do modelo estrutural de Yoo, Donthu e Lee (2000), a presente investigação procurou avaliar os antecedentes das Dimensões do Brand Equity (Qualidade Percebida, Lealdade de Marca, Consciência da Marca / Associações).

Foram investigados como antecedentes das Dimensões do Brand Equity os constructos: Preços, Imagem de Loja, Intensidade de Distribuição, Gastos em Publicidade e Preços Negociados.

A variável Preços não foi validada na Análise Fatorial Confirmatória, de tal forma que não há como estabelecer uma relação entre ela com a dimensão de Qualidade Percebida, não existindo evidências que suportem a hipótese H3a.

No que diz respeito à relação existente entre Imagem de Loja e constructos Qualidade Percebida (H3b) e Consciência da Marca / Associações (H3h), pode observar-se que os resultados coincidem com o esperado. Segundo os estudos, os consumidores vinculam uma boa imagem de loja com a qualidade percebida no produto. Mais do que isso, "distribuir uma marca a partir de um ponto de venda com boa imagem irá criar mais associações positivas à marca, do que através de uma loja mal estruturada." (YOO; DONTHU; LEE, 2000, p. 199). Dessa forma, as hipótese H3b e H3h são suportadas pelo presente estudo.

Observando as relações existentes entre a variável Intensidade de Distribuição e os seus consequentes, Qualidade Percebida (H3c), Lealdade de Marca (H3f), Consciência da Marca / Associações (H3i), contrariamente ao que é descrito na literatura sobre o tema, os resultados das hipóteses não se mostraram significativos, isto é, não suportam as hipóteses propostas.

A despeito da validade do constructo, parte do que é explorado neste conceito está relacionado a uma maior disponibilidade do produto comparada com a de marcas concorrentes (questões ID1 e ID2). Contudo, no mercado dos vinhos do Porto, não existem evidências que possam apontar uma maior disponibilidade de uma marca em relação à sua marca concorrente: ambas acabam por serem distribuídas de maneira mais ou menos homogênea nas diferentes superfícies comerciais (sejam grossistas, sejam retalhistas de bens de consumos gerais e/ou bebidas, sejam nas garrafeiras especializadas). No inquérito por questionário, apenas a questão ID3 aborda de forma isolada se a marca é distribuída por meio de um grande número de lojas possíveis. Nesta questão, a qualificação média foi superior as demais $(\mathrm{M}=4,94$, DP: 1,545$)$.

No que diz respeito à relação existente entre os Gastos em Publicidade e os constructos Qualidade Percebida (H3d), Lealdade de Marca (H3g) e Consciência da Marca / Associações $(\mathrm{H} 3 \mathrm{j})$, pode observar-se que os resultados coincidem com o esperado. Segundo a literatura abordada, os consumidores percebem no maior investimento em publicidade um indício de uma maior preocupação das empresas em proporcionar produtos de qualidade. Mais do que isso, "a promoção comercial está posititivamente relacionada à lealdade de marca porque reforça as associações e atitudes vinculadas às marcas." (YOO; DONTHU; LEE, 2000, p. 200). De acordo com o resultado obtido, as hipóteses H3d, H3g e H3j são suportadas pelo presente estudo.

Relativamente às relações existentes entre os Preços Negociados e os constructos Qualidade Percebida e Consciência da Marca / Associações (H3e e H3k, respectivamente), pode-se observar que os resultados corrobam as hipóteses elaboradas. A variável Preços Negociados (PN) tem uma relação negativa com as variáveis citadas, uma vez que faz que os consumidores relacionem estas práticas com uma suposta baixa qualidade dos produtos, além do que essas campanhas "não duram o suficiente 
para estabelecer associações de marca de longo prazo, que podem ser obtidas por outros esforços como pela publicidade e gestão de vendas." (YOO; DONTHU; LEE, 2000, p. 200). Dada a significância nos testes realizados, as hipóteses H3e e H3k são confirmadas.

\subsubsection{Análise dos consequentes das Di- mensões de Brand Equity}

Seguidamente, apresentamos os resultados da análise feita aos consequentes das Dimensões de Brand Equity. Foram investigados as relações dos constructos: Qualidade Percebida, Lealdade de Marca e Consciência da Marca / Associações com o Brand Equity.

No que diz respeito às relações existentes entre os constructos: Qualidade Percebida e Lealdade de Marca com o Brand Equity (H4a e $\mathrm{H} 4 \mathrm{~b}$, respectivamente), pode-se observar que os resultados coincidem com a literatura revista, isto é, corrobam as hipóteses elaboradas.

Relativamente à relação existente entre a variável Consciência da Marca / Associações e seu consequente, o Brand Equity (H4c), contrariamente ao que é descrito na literatura sobre o tema, o resultado não é significativo, isto é, não suporta a hipótese proposta.

\subsubsection{Análise dos consequentes da di- mensão de Brand Equity}

Relativamente às relações existentes entre a dimensão de Brand Equity e o constructo Passa-palavra Positivo (H5a), pode-se observar que os resultados corrobam as hipóteses elaboradas. $\mathrm{O}$ constructo de Brand Equity é definido como "a diferença na escolha do consumidor entre uma marca específica de produto e um produto sem marca, com as mesmas características." (YOO; DONTHU; LEE, 2000, p. 196).

Assim sendo, é natural a relação com o constructo Passa-palavra Positivo pois "os consumidores tendem a dedicar-se de forma recíproca a uma resposta positiva a uma marca." (MORHART et al., 2014, p. 207). Com base nos resultados apurados, podemos afirmar que a hipótese H5a é suportada pelo presente estudo. Dessa forma, o Passa-palavra Positivo é corrobado como consequente da dimensão de Brand Equity.

\subsubsection{Análise dos efeitos moderadores da dimensão de Ceticismo de Marketing}

Seguidamente, apresentamos os resultados da análise feita aos efeitos moderadores da dimensão de Ceticismo de Marketing. Foram investigadas as relações do constructo Ceticismo de Marketing nas relações estabelecidas com os Gastos em Publicidade e a Autenticidade de Marca (H6a), Qualidade Percebida (H6b), Lealdade (H6c) e Consciência da Marca / Associações (H6d).

$\mathrm{Na}$ análise do efeito moderador da variável Ceticismo de Marketing entre os Gastos em Publicidade das marcas de vinho do Porto e a Autenticidade de Marca, podemos perceber que, em nenhum dos grupos analisados, existe impacto significativo, sendo $\mathrm{p}>0,05$ para ambos os grupos. Nesse sentido, a hipótese H6a não é suportada.

De maneira geral, considera-se expectável o resultado da não ocorrência de impacto entre as variáveis para o grupo com maior Ceticismo de Marketing, uma vez que o primeiro grupo reage de maneira menos positiva às campanhas publicitárias. Assim sendo, é natural que os efeitos do Gastos de Publicidade não exerçam influência nas variáveis analisadas, para os consumidores mais céticos. Esta foi a ocorrência para as hipóteses H6b e H6d, em que houve ainda a validação da hipótese para o grupo de baixo Ceticismo de Marketing.

Contudo, como podemos verificar na análise da hipótese H6c, apesar de o grupo ser considerado com maior Ceticismo de Marketing, a variável Gastos em Publicidade teve impacto significativo na variável Lealdade de Marca. Devemos lembrar, contudo, a forte presença do caráter emocional e experimental envolvido no consumo do vinho do Porto, quer dizer, apesar de serem incrédulos quanto à publicidade, são mais instruídas e, algumas vezes, 
até mesmo, de extratos sociais mais elevados e estão propensos a se influenciarem por esta promoção e reforçarem a lealdade de determinada marca.

\section{CONCLUSÕES}

Os principais resultados alcançados mostram que os Elementos do Marketing Mix que foram corroborados como antecedentes da dimensão de Autenticidade de Marca neste estudo foram a Imagem de Loja e a Intensidade de Distribuição.

Como consequentes para a dimensão de Autenticidade de Marca neste estudo, demonstraram significância estatística no teste de hipóteses as seguintes dimensões: Qualidade Percebida, Lealdade de Marca, Consciência de Marca / Associações e o Passa-palavra Positivo

$\mathrm{Na}$ análise de precedência das Dimensões do Brand Equity com os Elementos do Marketing Mix, foram corrobadas as seguintes relações: a variável Imagem de Loja tem uma relação positiva com as variáveis Qualidade Percebida e com a variável Consciência da Marca / Associações.

Os testes realizados indicam uma relação positiva entre as variáveis de Gastos em Publicidade com as variáveis Qualidade Percebida, Lealdade de Marca e Consciência da Marca / Associações. A variável Preços Negociados tem uma relação negativa sobre a variável Consciência da Marca / Associações e sobre a variável Qualidade Percebida, corrobando as hipóteses relacionadas.

As Dimensões de Brand Equity que foram corroborados como antecedentes do Brand Equity neste estudo foram a Qualidade Percebida e a Lealdade de Marca.

Os resultados apurados nos testes das hipóteses de impacto/consequentes da dimensão de Brand Equity apontam uma relação positiva entre a mesma e a variável Passa-palavra Positivo, com um bom poder de explicação.

De forma a estudar o efeito moderador da variável Ceticismo de Marketing nas relações estabelecidas pelo Gastos em Publicida- de, utilizamos a análise de múltiplos grupos (Multiple-Group Analysis). Consideramos dois grupos distintos para a variável em questão, de acordo com os resultados médios informados nos inquéritos.

$\mathrm{Na}$ análise do efeito moderador da variável Ceticismo de Marketing entre os Gastos em Publicidade das marcas de vinho do Porto e a Autenticidade de Marca, podemos perceber que, em nenhum dos grupos analisados, verificou-se um impacto significativo, dessa forma, a hipótese não foi confirmada.

Nas relações estre as variáveis Gastos em Publicidade e as variáveis Qualidade Percebida e Consciência da Marca / Associações, percebemos um efeito da variável moderadora Ceticismo de Marketing.

$\mathrm{Na}$ análise do efeito moderador da variável Ceticismo de Marketing entre os Gastos em Publicidade das marcas de vinho do Porto e a Lealdade delas, percebemos a existência de uma relação positiva para o grupo com maior Ceticismo de Marketing.

Apesar da contrariedade do resultado, devemos considerar a forte presença do carácter emocional e experimental envolvido no consumo do vinho do Porto, quer dizer, o maior Ceticismo de Marketing está atrelado a um maior grau de instrução e, algumas vezes, até mesmo, de maiores extractos sociais e, nesse sentido, estão propensos a se influenciarem por esta promoção e reforçarem a lealdade de determinada marca.

\subsection{CONTRIBUTOS TEÓRICOS}

Como contributo esperado, conforme descrito na etapa de Justificação e Relevância do tema, nesta investigação, procuramos abordar a temática do vinho do Porto quanto à temática de Autenticidade de Marca. A despeito de ser este um produto de grande importância na história de Portugal e de expressiva representatividade econômica, boa parte da literatura evidencia a importância deste produto para ampliação das vantagens competitivas do país. As abordagens na temática de Marketing fazem 
maior referência aos aspectos dos rótulos das embalagens, do que propriamente às marcas.

Nesse sentido, relacionar este emblemático produto ao tema de Autenticidade de Marca, assunto este relativamente novo no ambiente de Marketing, possibilita, por si só, uma contribuição significativa. Outro grande contributo realizado por esta investigação foi promover a atualização dos dados relativamente à história do vinho do Porto. A obra de referência realizada por Martins (1990) apresentava o panorama histórico e econômico com estatísticas até o ano de 1988, isto é, este estudo, com apoio dos dados disponibilizadas pelo IVDP, consolidou quase três décadas de informações.

Acreditamos que o modelo conceptual proposto poderá ser utilizado futuramente para outros estudos, tais como os voltados para outros vinhos portugueses, tendo em vista a reputação nacional que têm conquistado no mercado internacional (seja os próprios vinhos do Douro, como também os produzidos em outras regiões, como de Setúbal, Bairrada entre outros).

Para além disso, a existência em Portugal de outros produtos possuidores de atributos de autenticidade, como azeite, queijos, produtos em louça etc., também favorece a possibilidade de se aplicar a base deste modelo.

\subsection{CONTRIBUIÇÕES PRÁTICAS}

Como anteriormente citado, a despeito dos quase três séculos de história, são poucos os estudos que abordam a temática das marcas do vinho do Porto. Boa parte desses estudos evidenciam a importância deste produto para ampliação das vantagens competitivas do país. As abordagens na temática de Marketing fazem maior referência aos aspectos dos rótulos das embalagens, do que propriamente às marcas. Em nossa investigação, utilizamos o conceito de Notoriedade Top-of-mind (TOMA - Top-of-mind awareness), definida como "a primeira marca que vem à mente do inquirido quando questionado sobre determinada categoria de produto." (HAKALA; SVENSSON; VINCZE, 2012, p. 442). A despeito de existirem diversas publicações que realizam estes estudos, apenas a Revista "Marcas que Marcam" direciona suas análises para o mercado dos vinhos do Porto. Nessa investigação, foram apuradas 27 marcas distintas de Vinho do Porto, em que foi apresentada uma listagem com as 10 marcas mais citadas, ordenadas por sua maior frequência. Apesar de muitos dos inquiridos fornecerem corretamente uma resposta adequada a essa pergunta, registramos a ocorrência de 61 indicações que não representam marcas de vinho do Porto (23,4\% do total). Grande parte dessas menções (36 indicações, 13,8\% do total) foram agrupadas como "Vinho do Porto", tendo em vista a indicação literal desta expressão ou os outros apontamentos. Ainda é notória a tradicional imagem associada ao vinho do Porto de quando imperava apenas a embalagem com a indicação do produto em si ("Port wine") e ao ano de colheita por meio do processo de serigrafia diretamente na garrafa. Acreditamos que, a despeito das particularidades de regulação promocional dos vinhos do Porto, esta investigação pode servir de base para que as organizações possam desenvolver suas ações publicitárias de forma a evidenciar seus atributos de Autenticidade de Marca.

\section{PORT WINE: BRAND AUTHENTICITY AS A PROMOTER FOR BRAND EQUITY}

\section{ABSTRACT}

This investigation aims at examining the role of brand authenticity as applied to one of the most important product of Portugal's economy, Port wine. Direct observation was employed as a technique. The research is based on data collected through a structured online questionnaire, in which 261 adults were surveyed. The article examines the relationship between brand authenticity, selected marketing mix elements and the creation of brand equity, according the model of Yoo, Donthu \& Lee (2000). To address this issue, the study aims at understanding the role that consumer authenticity perception, as well 
as its interaction with marketing strategies as perceived by consumers, might play in the formation of brand equity. Findings clearly indicate that the perception a consumer has regarding the authenticity of a brand is a critical determinant of dimensions of brand equity, and that brand equity has a significant impact on positive wordof-mouth. Findings of the present study would provide managers with a better understanding of the important role that authenticity plays in the formation of brand equity. The practical implications for better managing brand authenticity are also provided, as well as suggestions for suitable application of this study to other Portuguese products of relevance.

Keywords: Brands. Brand Authenticity. Port Wine. Brand Equity

\section{EL VINO DEL PORTO: LA AUTENTICIDAD DE LA MARCA COMO PROMOTORA DE LA EQUIDAD DE LA MARCA}

\section{RESUMEN}

Esta investigación tiene por objetivo examinar el papel de la autenticidad de la marca aplicada a uno de los productos más importantes en la economía de Portugal, el vino del Porto. Se utilizó la observación directa extensiva como técnica. La investigación tiene por base datos colectados por medio de un cuestionario estructurado, contestado en línea por 261 adultos. El artículo examina la relación entre la autenticidad de la marca, elementos mixtos de marketing seleccionados y la creación de la equidad de la marca, de acuerdo con el modelo de Yoo, Donthu \& Lee (2000). Para abordar este tema, el estudio tiene por objetivo comprender el papel que la percepción por el consumidor de la autenticidad de la marca, así como su interacción con las estrategias de marketing como percibidas por los consumidores, puede tener en la formación de la equidad de la marca. Los resultados claramente indican que la percepción que tiene un consumidor a respecto de la autentici- dad de una marca es un determinante crítico de dimensiones de la equidad de la marca, y que la equidad de la marca tiene impacto significante en boca a boca. Los resultados de la presente investigación aportarían a los gerentes mejor comprensión del papel importante que la autenticidad tiene en la formación de la equidad de la marca. También las implicaciones prácticas para mejor administrar la autenticidad de la marca son provistas, así como sugestiones para la aplicación adecuada de ese estudio a otros productos portugueses de relevancia.

Palabras-clave: Marcas. Autenticidad de la Marca. Vino del Porto. Equidad de la Marca.

\section{LE VIN DE PORTO: \\ L'AUTHENTICITE DE MARQUE COMME PROMOTRICE DE L'EQUITE DE MARQUE}

\section{RESUME}

Cette recherche a comme objectif de déterminer quel est le rôle de l'authenticité de marque appliquée à un des produits les plus importants dans l'économie du Portugal, le vin de Porto. Nous avons utilisé l'observation directe comme technique. La recherche est basée sur des données récoltées à travers un questionnaire structuré, répondu en ligne par 261 adultes. L'article évalue la relation entre l'authenticité de marque, des éléments mixtes de marketing sélectionnés et la création de l'équité de marque, selon le modèle de Yoo, Donthu \& Lee (2000). Pour aborder ce thème, l'étude a pour objectif de comprendre le rôle que la perception que le consommateur a de la marque, ainsi que son interaction avec les stratégies de marketing telles comme il les perceoit, peut avoir dans la formation de l'équité de marque. Les résultats indiquent clairement que la perception qu'un consommateur a à propos de l'authenticité d'une marque est un déterminant dans des dimensions de l'équité de la marque, et que l'équité de marque a un impact significatif sur le bouche à l'oreille. Les résultats de 
cette recherche apporteraient aux gérants une meilleure compréhension du rôle important que l'authenticité a dans la formation de l'équité de marque. Aussi les implications pratiques pour mieux administrer l'authenticité de la marque sont présentées, ainsi que des suggestions pour une application adéquate de cette recherche à d'autres produtis portugais de pertinence.

Mots-clés: Marques. Authenticité de marque. Vin de Porto. Equité de marque.

\section{REFERÊNCIAS}

AAKER, D. A. Building strong brands. New York: Free Press, 1996.

ABIMBOLA, T.; KOCAK, A. Brand, organization identity and reputation: SMEs as expressive organizations: A resources-based perspective. Qualitative Market Research: An International Journal, United Kingdom, v. 10, n. 4, p. 416-430, 2007.

ALBERT, N.; MERUNKA, D.; VALETTE-FLORENCE, P. When consumers love their brands: Exploring the concept and its dimensions. Journal of Business research, Netherlands, v. 61, p. 1062-1075, 2008.

ALLEN, T.; SIMMONS, J. Visual and verbal identity. In: CLIFTON, R.; SIMMONS, J. (Org.). Brands and branding. Londres: The Economist in association with Profile Books, 2003. p. 113-126.

BATRA, R.; AHUVIA, A.; BAGOZZI, R. P. Brand Love. Journal of Marketing, United States, v. 76, n. 2, p. 1-16, 2012.

BEVERLAND, M. B. Crafting brand authenticity: The case of luxury wines. Journal of Management Studies, United Kingdom. v. 42, n. 5, p. 1003-1029, 2005.

BEVERLAND, M. B.; FARRELLY, F. J. The Quest for Authenticity in Consumption: Con- sumers' Purposive Choice of Authentic Cues to Shape Experienced Outcomes. Journal of Consumer Research, United States, v. 36, n. 5, p. 838-856, 2010.

BRUHN, M. et al. Brand authenticity: Towards a deeper understanding of its conceptualization and measurement. Advances in Consumer Research, United States, v. 40, p. 567-576, 2012.

BUTTLE, F. A. Word of mouth: understanding and managing referral marketing. Journal of Strategic Marketing, United Kingdom, v. 6, n. 3, p. 241-254, 1998.

CARROLL, B. A.; AHUVIA, A. C. Some antecedents and outcomes of brand love. Marketing Letters, Netherlands, v. 17, n. 2, p. 79-89, 2006.

CHRISTODOULIDES, G.; CHERNATONY, L. de. Consumer-based brand equity conceptualization and measurement:a literature review. International journal of research in marketing, Netherlands, v. 52, n. 1, p. 43-66, 2010.

DIOGO, João. Marcating: gestão estratégica da marca. Lisboa: Paulus Editora, 2008.

ERDEM, T.; SWAIT, J. Brand Credibility, Brand Consideration, and Choice. Journal of Consumer Research, United States, v. 31, n. 1, p. 191-198, 2004.

EGGERS, F. et al. The impact of brand authenticity on brand trust and SME growth: A CEO perspective. Journal of World Business, United Kingdom, v. 48, n. 3, p. 340-348, 2013.

FRAZIER, G. L.; LASSAR, W. M. Determinants of Distribution Intensity. Journal of Marketing, United States, v. 60, n. 4, p. 39, 1996.

FRITZ, K.; SCHOENMUELLER, V.; BRUHN, M. Authenticity in branding-exploring antecedents and consequences of brand authenticity. European Journal of Marketing, 
v. 51, n. 2, p. 324-348, 2017.

HAKALA, U.; SVENSSON, J.; VINCZE, Z. Consumer based brand equity and top of mind awareness: a cross country analysis. Journal of Product \& Brand Management, United Kingdom, v. 21, n. 6, p. 439-451, 2012.

KELLER, K. L. Strategic brand management: building, measuring, and managing brand equity. 4th ed. United Kingdom: Pearson Education, 2013.

KOTLER, P.; KELLER, K. L. Marketing Management. $14^{\text {th }}$ ed. United States: Prentice Hall, 2012.

LU, A. C. C.; GURSOY, D.; LU, C. Y. Authenticity perceptions, brand equity and brand choice intention: the case of ethnic restaurants. International Journal of Hospitality Management, United Kingdom, v. 50, p. 36-45, 2015.

MARÔCO, J. Análise de equações estruturais: fundamentos teóricos, software \& aplicações. 2. ed. Pêro Pinheiro: ReportNumbe, 2014.

MARTINS, C. A. Memória do Vinho do Porto. Lisboa: Instituto de Ciências Sociais da Universidade de Lisboa, 1990.

MAXIAN, W. et al. Brand love is in the heart: Physiological responding to advertised brands. Psychology \& Marketing, United States, v. 30, p. 469-478, 2013.

MORHART, F. et al. Brand authenticity: an integrative framework and measurement scale. Journal of Consumer Psychology, United states, v. 25, n. 2, p. 200-218, 2014.

MOULARD, J. G.; RAGGIO, R. D.; FOLSE, J. A.G. Brand Authenticity: Testing the Antecedents and Outcomes of Brand Management's Passion for its Products. Psychology \&
Marketing, v. 33, n. 6, p. 421-436, 2016.

OBERMILLER, C.; SPANGENBERG, E. R. Development of a scale to measure consumer skepticism toward advertising. Journal of consumer psychology, v. 7, n. 2, p. 159-186, 1998.

PARK, C. W. et al. Brand attachment and brand attitude strength: conceptual and empirical differentiation of two critical brand equity drivers. Journal of Marketing, United States, v. 74, n. 6, p. 1-17, 2010.

ROSE, R. L.; WOOD, S. L. Paradox and the Consumption of Authenticity through Reality Television. Journal of Consumer Research, United States, v. 32, n. 2, p. 284-296, 2005.

SEETHARAMAN, A. et al. A conceptual study on brand valuation. Journal of product \& brand Management, United Kingdom, v.10, p. 243-256, 2001.

SUNG, Y.; KIM, J. Effects of brand personality on brand trust and brand affect. Psychology \& Marketing, United States, v. 27, n. 7, p. 639661, 2010.

URDE, M.; GREYSER, S. A.; BALMER, J. M. T. Corporate Brands with a Heritage. Journal of Brand Management, United Kingdom, v. 15, n. 1, p. 4-19, 2007.

YOO, B.; DONTHU, N.; LEE, S. An Examination of Selected Marketing Mix Elements and Brand Equity. Journal of the Academy of Marketing Science, United States, v. 28, n. 2, p. 195-211, 2000. 